\title{
Professional Development Coaching for Residents: Results of a 3-Year Positive Psychology Coaching Intervention
}

\author{
Kerri Palamara, $M D^{7}$, Carol Kauffman, $P h D^{2,3}$, Yuchiao Chang, PhD ${ }^{7}$, Esteban A. Barreto, $M A^{4}$, \\ Liyang Yu, MS ${ }^{7}$, Hasan Bazari, $\mathrm{MD}^{7}$, and Karen Donelan, SCD, EdM ${ }^{4}$ \\ 'Department of Medicine, Massachusetts General Hospital, Boston, MA, USA; ${ }^{2}$ Department of Psychiatry, Harvard Medical School, Boston, MA, \\ USA; ${ }^{3}$ Institute of Coaching, McLean Hospital, Belmont, MA, USA; ${ }^{4}$ Mongan Institute Health Policy Center, Massachusetts General Hospital, Boston, \\ MA, USA.
}

KEY WORDS: burnout; medical education-professionalism; medical education-mentoring; curriculum/program evaluation; medical education-graduate.

J Gen Intern Med 33(11): 1842-4

DOI: $10.1007 /$ s11606-018-4589-1

(C) Society of General Internal Medicine 2018

\section{INTRODUCTION}

Residents are more likely to experience burnout compared to their age-matched peers. ${ }^{1}$ The Accreditation Council of Graduate Medical Education (ACGME) has mandated that residency programs address resident and faculty well-being through their Clinical Learning Environment Review (CLER) program. ${ }^{2}$

Positive psychology coaching can help residents connect with and achieve positive emotions, meaningful relationships, strengths, engagement, and purpose. ${ }^{3}$ We implemented the Professional Development Coaching Program (PDCP) in our internal medicine residency program in 2012 and demonstrated a reduction in intern emotional exhaustion (EE) after year $1 .{ }^{4}$ In this paper, we report on the experiences of residents after year 3 .

\section{METHODS}

\section{Setting and Participants}

The PDCP included 179 residents who were assigned a coach in the 2014-2015 academic year. Pairs were expected to meet quarterly and participation was logged administratively. We define full participation as $\geq 3$ meetings per year; there was no consequence for not participating.

\section{Intervention}

Using positive psychology and coaching principles, the PDCP trains volunteer faculty "coaches" to work with resident "coachees," intentionally matched outside of their discipline. Coaches were provided with a guide for each meeting. All meetings included reflection on experiences, goal-setting, and directions for engaging in a positive psychology coaching dialogue. Annually, each initial meeting focused on what personal and professional success would look like for that academic year, and ended with reflection on accomplishments. Year 1 included strengths exploration, coping with stress through building resilience, and finding engagement and meaning in their work. Year 2 added development of leadership capabilities and emotional intelligence. Year 3 added authentic leadership, finding their passion and purpose, and cultivating life's lessons.

\section{Measures}

The measures used to assess the program process included (1) participation (administrative data), (2) communication (survey), and (3) reflection (survey). PDCP outcomes were (1) improved coping skills; (2) improved perception of professional roles/relationships; (3) decreased (EE) on the Maslach Burnout Inventory; (4) coachee experience; and (5) residency satisfaction. ${ }^{5,6}$

Table 1 Coaching Program Measures and Coping

\begin{tabular}{|c|c|c|c|c|c|c|c|}
\hline \multirow[t]{2}{*}{ Trainee challenges } & \multicolumn{3}{|c|}{ Participation } & \multicolumn{4}{|c|}{ Quality of communication with a coach } \\
\hline & Full (\%) & Partial (\%) & $p$ value & Excellent (\%) & Good $(\%)$ & Fair/poor (\%) & $p$ value \\
\hline Coping with stress & 70 & 35 & 0.0004 & 73 & 44 & 12 & 0.0001 \\
\hline Distress in personal life & 80 & 51 & 0.002 & 86 & 56 & 24 & 0.0001 \\
\hline Information processing & 67 & 35 & 0.001 & 78 & 30 & 6 & 0.0001 \\
\hline Work-life balance & 70 & 28 & 0.0001 & 66 & 44 & 18 & 0.001 \\
\hline Work relationships & 70 & 40 & 0.002 & 78 & 33 & 24 & 0.0001 \\
\hline Self-confidence & 85 & 53 & 0.0005 & 88 & 67 & 24 & 0.0001 \\
\hline Administrative burdens & 45 & 14 & 0.001 & 51 & 7 & 6 & 0.0001 \\
\hline
\end{tabular}

The survey stated the following: "In previous research, the following have been noted as major challenges for trainees. For each one, please indicate if you believe the coaching program has improved your ability to cope." Responses were examined by resident participation and quality of communication with coach 


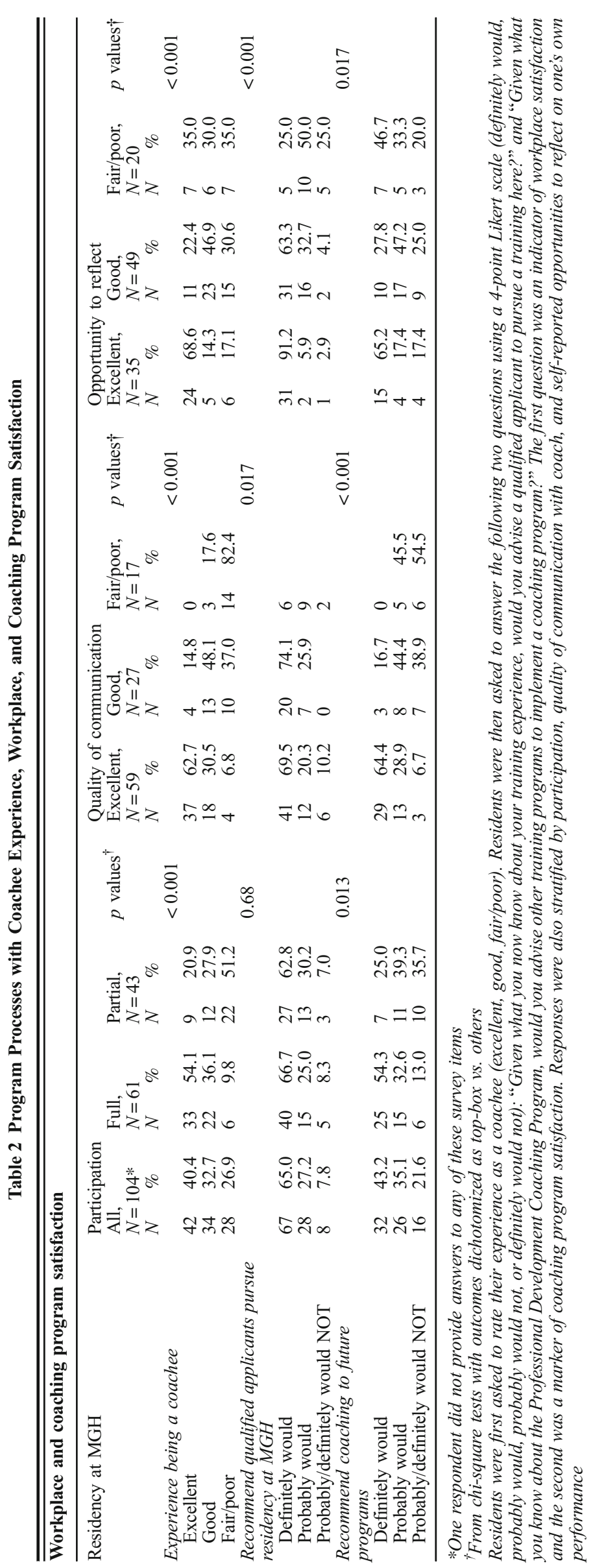




\section{RESULTS}

Characteristics of respondents and non-respondents were similar in terms of age, race, ethnicity, program year, and EE. Fifty-six percent were full participants. Survey completion and coaching participation were greatest in first and third years; $81.9 \%$ rated communication with coach as "excellent or good" and $80.0 \%$ reported "excellent or good" opportunities for reflection.

\section{Perceived Coping Skills, Roles, and Relationships}

Residents who participated fully in the program and had positive quality of communication with their coach were significantly more likely to report higher coping skills and better working relationships in several dimensions (Table 1).

\section{Emotional Exhaustion}

Residents who reported fair/poor opportunities for reflection were more likely to report high EE ( $85.0 \%$ vs. $44.9 \%$ from those reported good opportunities or $31.4 \%$ from those reported excellent opportunities, $p<0.001)$. EE did not differ by program year or full vs. partial participation.

\section{Coachee Experience and Residency Program Satisfaction}

Overall, $73.1 \%$ of coachees reported excellent/good experiences being a coachee, $92.2 \%$ of coachees would "definitely or probably recommend" our residency program to an incoming applicant, and $78.3 \%$ would "definitely or probably recommend" a coaching program to other residencies. Table 2 shows bivariate relationships of process and outcome measures. Extent of participation was significantly associated with an "excellent" overall experience of being a coachee $(54.1 \%$ vs $20.9 \%, p<0.001)$. Those with excellent opportunities for reflection were more likely to report excellent experience of being a coachee $(68.6 \%$ vs. $35.0 \%, p<0.001)$; more likely to "definitely recommend" the residency program to others ( $91.2 \%$ vs. $25.0 \%, p<0.001$ ); and more likely to definitely recommend the PDCP program ( $65.2 \%$ vs. $46.7 \%, p=0.017)$.

\section{DISCUSSION}

We implemented a positive psychology coaching program in a large internal medicine residency. Most residents participated fully. We observed a significant association between a positive program experience, opportunities to reflect, and positive residency experience, as well as increased coping and relationship skills.

While we measure several significant bivariate associations in this cross-sectional sample, our single-site study is limited by the small number of coaches with paired 3-year follow-up data. This limits longitudinal multivariate analyses on the full 3-year cohort.

The ACGME CLER Program now mandates that residency programs have mechanisms in place to assess and address resident burnout and well-being. Positive psychology coaching, using a strengths-based approach, provides participants with additional tools required to cope with the substantial personal and professional stressors they face during their residency.

Acknowledgments: The authors wish to thank the faculty coaches and resident participants who engaged in the program, as well as the Department of Medicine for their support in developing and onboarding this program. The authors wish to express gratitude to the Dr. George Thibault and the Josiah H. Macy Foundation, as well as the Arthur Vining Davis Foundation, for the financial support for our program evaluation. The authors wish to acknowledge the Institute of Coaching for their expertise in designing and implementing this program.

Corresponding Author: Kerri Palamara, MD; Department of Medicine Massachusetts General Hospital, Boston, MA, USA (e-mail: kpalamara@partners.org).

Funders The Josiah H. Macy Foundation provided \$35,000 of funding through a President's Grant to support the establishment and investigation of this program. The Arthur Vining Davis Foundation provided $\$ 100,000$ of funding through a Healthcare Grant to support the investigation and dissemination of this program.

\section{Compliance with Ethical Standards:}

Conflict of Interest: The authors declare that there is no conflict of interest.

Data Sharing: Data sharing was not applicable to this article as no datasets were generated or analyzed during the current study.

Ethical Approval: This program and its evaluation were exempt by the institutional review board with exemption \#45 CFR 46.101(b) (1). The research was conducted in established or commonly accepted educational settings, involving normal educational practices.

Prior Presentations: While the tools and implementation process used in the coaching program have been shared in numerous workshops at national conferences (Society of General Internal Medicine, Association of Program Directors in Internal Medicine, American College of Physicians) and invited faculty development workshops, the data included in this paper has not been previously presented.

Abbreviations

ACGME Accreditation Council of Graduate Medical

Education

CLER Clinical Learning Environment Review

EE emotional exhaustion

MBI Maslach Burnout Inventory

PDCP Professional Development Coaching Program

\section{REFERENCES}

1. Dyrbye LN, West CP, Satele D, Boone S, Tan L, Sloan J, Shanafelt TD. Burnout among US medical students, residents, and early career physicians relative to the general US population. Acad Med 2014;89(3):443-51.

2. Accreditation Council for Graduate Medical Education. CLER Pathways to Excellence. https://www.acgme.org/Portals/0/PDFs/CLER/CLER_Brochure.pdf. Accessed 12 April 2017.

3. Butler J, Kern ML. The PERMA-Profiler: a brief multidimensional measure of flourishing. Int $J$ Wellbeing 2016; 6(3): 1-48.

4. Palamara K, Kauffman C, Bazari $\mathbf{H}$, Stone V, Donelan $\mathbf{K}$. Promoting success: a professional development coaching program for interns in medicine. JGME 2015; 7(4);630-7.

5. Perlo J, Balik B, Swensen S, Kabcenell A, Landsman J, Feeley D. IHI Framework for Improving Joy in Work. IHI White Paper. Cambridge, Massachusetts: Institute for Healthcare Improvement; 2017.

6. Maslach C, Schaufeli W, Leiter M. Job burnout. Annu Rev Psychol 2001;52(1), 397-422. 